Check for updates

1 University College London

2 Department of Behavioural Science and Health, University College London

Cite this as: $B M J 2021 ; 375: n 3063$ http://dx.doi.org/10.1136/bmj.n3063 Published: 10 December 2021

\title{
Protecting the mental health of groups needing NHS care this winter
}

\section{Alexandra Burton, ${ }^{1}$ Alexandra Bradbury ${ }^{2}$}

The sudden return to coronavirus restrictions to protect the UK from the latest "heavily mutated" covid-19 variant will only add to the trepidation that many have been feeling in the lead-up to winter. ${ }^{1} \mathrm{As}$ the medical community continues to call for more action from the government and the NHS buckles under unsustainable demand, the public waits for signs that the winter will bring a return to familiar stay-at-home orders and sudden changes to Christmas plans. $^{2}$

There has been enough research during the pandemic for us to know that mental health will be important to protect in the coming months. NHS triaging, waitlists, and slow care will have a direct impact on our lives. Levels of anxiety and depression, which have remained stubbornly stable since the spring, will probably start to rise. ${ }^{3}$ But particular groups will be more affected than others by any cancellations or changes in treatment and they need to be prioritised and monitored as we approach this "hard" time to come.

These include people with mental health conditions, pregnant women, and those managing chronic illnesses who during the peaks of the pandemic were left vulnerable and with few options. What they have in common is a reliance on regular contact with health services. People who were already receiving treatment for mental health issues, suddenly found that their usual care and medications were halted or that health professionals were slow to continue their support. ${ }^{4}$ Telephone or online consultations were considered inferior or even inappropriate and upsetting for people with deteriorating mental health. ${ }^{5}$ Even more worryingly, some health professionals have described an impaired ability to pick up on signs of declining mental health without being able to see patients in person. This was likely exacerbated by the "protect the NHS" messaging, which implied that mental health was not essential and that patients should forgo their usual care. Significant reductions in presentations to A\&E suggested this was the case for people with severe mental illness who most likely found themselves with nowhere to turn for support in an emergency. ${ }^{6} \mathrm{We}$ can't let people with mental health issues face the same alarming roadblocks this coming winter.

Similarly, people with chronic illnesses remained at home during the pandemic even while experiencing worrying symptoms. Many felt extremely vulnerable and were particularly worried about catching covid-19 and their increased risk of death. ${ }^{7}$ At the same time, many were concerned that without having any physical assessments, their clinicians would miss important health signs. ${ }^{8}$ Others were anxious that being locked down at home would exacerbate their health problems. ${ }^{9}$ The mental health impact of these uncertainties surrounding covid-19 were particularly strong for this group, and continuity of care, not just for their long term illnesses but for managing the impact of disrupted treatment on their mental health, will be extremely important.

Finally, women who were pregnant during the pandemic faced considerable disruptions to their care. Lockdown exacerbated new mothers' sense of isolation and loss of independence. ${ }^{10}$ At a time when women are especially reliant on emotional and social support, many found themselves unable to receive that support or guilty when they did seek it out. Guilt also played a role in clinical care. They often felt they couldn't ask for help from health professionals-even after facing long wait times for prenatal appointments and substandard care after childbirth. ${ }^{11}$ This was exacerbated by rules that excluded partners from attending healthcare appointments, which was traumatic for women, especially if they had to manage labour by themselves.

Protecting mental health during this uncertain time and building public confidence can be achieved with a more nuanced understanding of the consequences of removing care from vulnerable groups whose trust in the government and the NHS has been shaken during the pandemic. As we brace ourselves for what may come this season, we should remember to listen to the mental health needs of groups most reliant on consistent mental and physical healthcare.

\section{Competing interests: none declared}

Provenance and peer review: not commissioned, not peer reviewed

Torjesen I. Covid restrictions tighten as omicron cases double every two to three days. BMJ2021;375. doi: 10.1136/bmj.n3051

2 Ham C. A national infrastructure plan for the NHS, social care, and public health is needed to build resilience for the future. BMJ2021;375. doi: 10.1136/bmj.n3029

3 Fancourt D, Bu F, Wan Mak H, Paul E, Steptoe A. Covid-19 Social Study, Results Release 40. https://b6bdcb03-332c-4ff9-8b9d28f9c957493a.filesusr.com/ugd/064c8b_86930bad37754dc9ac0553ef44caa902.pdf

4 Gillard S, Dare C, Hardy J, etalNIHR Mental Health Policy Research Unit Covid coproduction research group. Experiences of living with mental health problems during the COVID-19 pandemic in the UK: a coproduced, participatory qualitative interview study. Soc Psychiatry Psychiatr Epidemiol 2021;56:1447-57. doi: 10.1007/s00127-021-02051-7. pmid: 33665680

5 Burton A, McKinlay A, Aughterson H, Fancourt D. Impact of the COVID-19 pandemic on the mental health and well-being of adults with mental health conditions in the UK: a qualitative interview study. J Ment Health 2021;1-8. doi: 10.1080/09638237.2021.1952953. pmid: 34323635

$6 \quad$ NHS England. A\&E Attendances and Emergency Admissions April 2020 Statistical Commentary. https://www.england.nhs.uk/statistics/wp-content/uploads/sites/2/2020/05/Statistical-commentary-April-2020-jf8hj.pdf Philip KEJ, Lonergan B, Cumella A, Farrington-Douglas J, Laffan M, Hopkinson NS. COVID-19 related concerns of people with long-term respiratory conditions: a qualitative study. BMC Pulm Med 2020;20:319. doi: 10.1186/s12890-020-01363-9. pmid: 33298023

8 Fisher A, Roberts A, McKinlay AR, Fancourt D, Burton A. The impact of the COVID-19 pandemic on mental health and well-being of people living with a long-term physical health condition: a qualitative study. BMC Public Health 2021;21:1801. doi: 10.1186/s12889-021-11751-3. pmid: 34620136 


\section{OPINION}

9 Simpson J, Zarotti N, Varey S, etal. 'It's a double whammy': A qualitative study of illness uncertainty in individuals with Parkinson's disease in the context of COVID-19. Chronic Illn

2021;(September):17423953211043101. doi: 10.1177/17423953211043101. pmid: 34524910

10 Jackson L, De Pascalis L, Harrold JA, Fallon V, Silverio SA. Postpartum women's psychological experiences during the COVID-19 pandemic: a modified recurrent cross-sectional thematic analysis. BMC Pregnancy Childbirth 2021;21:625

doi: 10.1186/s12884-021-04071-2. pmid: 34530772

11 McKinlay AR, Fancourt D, Burton A. Factors affecting the mental health of pregnant women using UK maternity services during the COVID-19 pandemic: A qualitative interview study [preprint]medRxiv 2021.10.20.21265279doi: 10.1101/2021.10.20.21265279. 